\title{
CONSECUENCIAS DE LAS INTERPRETACIONES ACTUALES DE la Metafísica Humeana en El Debate Sobre las Leyes de LA NATURALEZA
}

BRUNO BORGE

ROBERTO AZAR

\begin{abstract}
A highly influential position in the debate between nomological realists and antirealists (i.e., the debate about the metaphysical status of natural laws) is the regularist theory of laws. Its main feature is the defense of a humean metaphysics which denies the existence of real causal powers and necessary connections in nature. Regularism, however, rely on a traditional reading of Hume's philosophy. In this paper we aim to revisit the discussion around laws of nature in light of nontraditional interpretations of his work, often labeled as the 'New Hume'.
\end{abstract}

Keywords: Laws of Nature; nomological realism; Hume; Humeanism; sceptical realism.

\section{Introducción}

La constatación de la centralidad del debate sobre las leyes de naturaleza en el ámbito de la Filosofía de la Ciencia no es novedosa, pues pueden rastrearse esfuerzos tendientes a distinguir apropiadamente las leyes genuinas de las generalizaciones accidentalmente verdaderas ya en épocas sorprendentemente tempranas del desarrollo de la disciplina. Sin embargo, la cuestión de las leyes naturales adquiere un relieve decididamente metafísico recién a fines del siglo pasado cuando se configuran con claridad dos polos que definen las coordenadas del debate contemporáneo. Por una parte, los realistas nomológicos afirman que las regularidades empíricamente constatables, aquellas que permiten la formulación de las teorías científicas, son adecuadamente explicadas por la existencia objetiva de leyes naturales que dotan de algún tipo de necesidad al comportamiento regular de los fenómenos. Así, el enfoque de los universales de David Armstrong (1978; 1983; 1991; 1993), como así también el de Fred Dretske (1977) y el de Michael Tooley (1977; 1987), podrían ubicarse en esta línea argumentativa. Los antirrealistas nomológicos, por otra parte, sostienen que la comprobación de la regularidad de la naturaleza resulta suficiente para la ciencia y no nos compele a postular la existencia de entidades dudosas tales como las leyes. Esta última línea, que se suele asociar a las posiciones regularistas en Filosofía de la Ciencia, presupone una interpretación tradicional de la filosofía de David Hume, interpretación que, a partir de la década de 1980, comenzó a ser cuestionada por la visión del 'Nuevo Hume'. La interpretación tradicional abarca una

Principia 19(2): 247-262 (2015).

Published by NEL — Epistemology and Logic Research Group, Federal University of Santa Catarina (UFSC), Brazil. 
variedad de posiciones, pero todas ellas comparten un 'corazón común', consistente en una tesis positiva y una negativa. La primera sostiene que Hume afirma que la causación en los objetos es una cuestión tan sólo explicable en términos de prioridad temporal, contigüidad y conjunción constante: nuestro modo de hablar y nuestro pensamiento causal no pueden tener éxito en describir o referir a algo más en el mundo que esas características. La tesis negativa, por su parte, afirma que resulta ilegítimo o incoherente aplicar la idea de conexión necesaria a los eventos externos. Estas dos tesis, por sí mismas, son suficientes para distinguir la interpretación tradicional de la novedosa interpretación que, por el contrario, presupone que Hume fue un realista de algún tipo acerca de los poderes causales y los objetos externos. El debate actual, en consecuencia, se configura entre aquellos que leyeron a Hume como un escéptico epistémico estricto sobre estas cuestiones y aquellos que apoyan la interpretación del 'Nuevo Hume'. Los nuevos humeanos incluyen, entre otros, a Galen Strawson (1989) y John Wright (1983). Estos autores, en general, atribuyen a Hume lo que ellos llaman una visión 'realista escéptica' respecto de las causas (y de ciertas otras entidades). Veremos más adelante que esta polémica visión sería mejor caracterizada, a nuestro juicio, como la combinación de un realismo metafísico y un antirrealismo epistémico.

En el presente trabajo nos proponemos evaluar, en primer lugar, si resulta plausible formular el 'realismo escéptico' de los nuevos humeanos en términos del debate sobre las leyes de la naturaleza. Si la respuesta es afirmativa, en segundo lugar, será menester analizar si alguna de las múltiples posiciones que forman parte de la contienda que enfrenta a realistas y antirrealistas nomológicos encarna propiamente las tesis sostenidas por un hipotético realista escéptico.

\section{Realismo y Antirrealismo Nomológicos}

\subsection{Mapa general del debate}

Teniendo en cuenta que el término griego nómos significa "ley", resulta esperable que en el ámbito de la Filosofía de la Ciencia llamemos realistas nomológicos sólo a aquellos autores que postulen la existencia objetiva de leyes de naturaleza, en tanto que consideremos antirrealistas nomológicos a quienes nieguen rotundamente, o al menos se declaren agnósticos con respecto a, la presencia efectiva de leyes naturales en el elenco metafísico de la realidad.

Se adelantó en la Introducción que la cuestión de la naturaleza de las leyes, y en especial la relevancia de su adecuada diferenciación con respecto a las generalizaciones tan sólo accidentalmente verdaderas, preocupó a los filósofos desde épocas muy precoces. Tal es así que se pueden registrar en la literatura temprana múltiples esfuerzos tendientes a brindar condiciones suficientes y necesarias que sean capaces de

Principia 19(2): 247-262 (2015). 
respaldar conceptualmente la diferencia intuitiva que parece existir entre enunciados que describen regularidades que expresan correlaciones necesarias entre propiedades (por ejemplo, entre 'ser un metal' y 'dilatarse con el calor') y enunciados que, por el contrario, expresan correlaciones factualmente constantes, pero absolutamente contingentes (por ejemplo, 'ser un filósofo de la ciencia' y 'beber mucha cerveza'). Poco a poco, sin embargo, la preeminencia de los frecuentemente estériles enfoques lógico-sintácticos en Filosofía de la Ciencia fue cediendo su lugar a las consideraciones propiamente metafísicas en torno a la necesidad natural. En esta línea, se hizo preciso distinguir categorías que históricamente habían sido confundidas. Por ejemplo, las nociones de 'ley natural' (cierta entidad, rasgo o propiedad efectivamente existente en la realidad) y 'ley científica' (el enunciado legaliforme capaz de describirla adecuadamente). Sentado el perfil metafísico que culmina asumiendo el asunto que nos ocupa, procedamos entonces a catalogar las variadas posiciones en juego.

Ante la constatación de las regularidades empíricas del mundo natural que nos alberga, y la demanda de explicación, históricamente se han asumido diferentes actitudes que configuraron posiciones discordantes. A grandes rasgos, podemos distinguir dos grupos de enfoques: por un lado, el Antirrealismo Nomológico (en adelante, AN), en sus múltiples variantes, no consiente en comprometerse con la existencia objetiva de leyes naturales - entendidas como cosas efectivamente existentes en la realidad - , ya que sus defensores creen que una ontología más modesta resulta suficiente para dar cuenta de los mismos hechos. Por otro lado, el Realismo Nomológico (en adelante. RN) es un enfoque de universales que postula la existencia objetiva de leyes naturales, las únicas que serían realmente capaces de fundamentar adecuadamente la regularidad del mundo.

Comenzando por el AN, el 'regularismo humeano' afirma que la regularidad empírica es tan sólo un factum que no requiere ninguna explicación adicional. No hay razones para suponer que el mundo contenga conexiones necesarias entre eventos ni mucho menos entidades tales como las leyes naturales. Este espíritu empirista heredero de una interpretación tradicional de la filosofía de David Hume podría hacernos pensar en la completa ausencia de una propuesta metafísica. Sin embargo, este no es el caso. Según los regularistas humeanos, el mundo estaría compuesto por eventos discretos, cada uno de los cuales se autocontiene y existe con total independencia del resto. Lo único que hay son cosas aisladas entre las cuales es perfectamente posible hallar ciertas regularidades factualmente constantes —esa será la tarea de la investigación empírica-, pero ello no implica que haya una conexión interna que vincule necesariamente ciertas cosas entre sí ni una conexión externa del sistema total de la naturaleza implicando alguna distribución en particular y no cualquier otra posible. Un AN menos radicalmente empirista intenta conciliar este vacío nomológico con la posibilidad de distinguir apropiadamente los enunciados legaliformes de aquellos enunciados que expresan meras regularidades accidentales. Nos referimos 
a la 'teoría de los mejores sistemas' o 'teoría MRL' (Mill-Ramsey-Lewis), según la cual son auténticas leyes sólo aquellos enunciados que figuran en los mejores sistemas deductivos, es decir, aquellos que logran la mejor combinación de simplicidad y fuerza (Lewis 1973, p.73). De esta manera, podríamos fundamentar apropiadamente el pensamiento de que es una ley que 'todas las esferas de uranio tienen menos de una milla de diámetro' sin apelar a necesidades de re, sino tan sólo al hecho de que aquel enunciado forma parte del mejor sistema deductivo del que disponemos en un área determinada. Finalmente, el AN también es compatible con una metafísica disposicionalista (Cartwright 1980; Mumford 2004) que afirma la existencia de conexiones necesarias en la naturaleza, pero no de entidades tales como las leyes. Según esta propuesta, los poderes y disposiciones dotan al mundo de la efectividad causal que se requiere para fundamentar ontológicamente las regularidades empíricas. En el marco de esta posición, las propiedades deben ser entendidas como clusters de poderes/disposiciones. De este modo, que un particular sea F implica que también sea $\mathrm{G}$ en virtud de una necesidad inmanente a la constitución metafísica de F qua propiedad. Así son presentados los poderes, como pudiendo hacer todo el trabajo que harían las leyes con un costo metafísico menor.

Con respecto al $\mathrm{RN}$, en cualquiera de sus variantes, sostiene que nuestro mundo contiene no sólo conexiones necesarias entre propiedades, sino también leyes que las sustentan. El punto es que la naturaleza de esas leyes ha sido esclarecida de formas diferentes, lo que ha dado lugar a dos visiones diferenciadas: según la concepción internalista, defendida por Brian Ellis, las leyes son internas a sus instancias, más específicamente son las propiedades esenciales de las clases naturales. Así, todas las leyes de naturaleza se derivan de las propiedades esenciales de los objetos y eventos que las constituyen (Ellis 2001, p.4). Otra alternativa es adoptar una concepción externalista de las leyes, según la cual estas serían externas a sus instancias, sobre las cuales ejercerían una especie de gobierno. Los filósofos Dretske, Tooley y Armstrong (abreviadamente teoría DTA) adoptan el realismo nomológico en su versión externalista, pues para todos ellos una ley natural —que puede ser expresada a través de un enunciado legaliforme L- es externa y consiste en una relación de segundo orden entre dos propiedades o universales. Así, afirmar L, equivale a decir, por ejemplo, que es una ley natural que "Todos los F son G", y esta afirmación involucra la existencia de dos universales F y G y además una relación $\mathrm{N}$ de segundo orden que los vincula, a menudo llamada "relación de necesitación". Por lo tanto, lo que hace que L sea verdadero es el hecho de que F está relacionado con $\mathrm{G}$ por $\mathrm{N}$ (o que F necesita $\mathrm{G}$ ).

\subsection{Humeanismo en el debate sobre las leyes}

La forma más radical de AN, como vimos, adopta el marco de una metafísica humeana. Abordar con cierto detalle las posiciones que encarnan esta parcela del debate

Principia 19(2): 247-262 (2015). 
requiere de algunas aclaraciones que resultan previas incluso a lo que debería ser el punto de partida. La expresión metafísica humeana, por ejemplo, podría tomarse lisa y llanamente por un oxímoron. Después de todo, ¿qué posición especulativa puede surgir de la obra de quien nos invitó a arrojar al fuego los volúmenes de metafísica por no contener más que sofistería e ilusión? La constitución de una metafísica humeana debe leerse como un intento de extrapolar las consecuencias de la epistemología de Hume al ámbito de la discusión contemporánea respecto de las variadas cuestiones ligadas a la metafísica de la modalidad (e.g. las condiciones de verdad de los enunciados modales y contrafácticos, la causalidad y las leyes naturales). Más precisamente se procuró levantar como estandartes las conclusiones escépticas de Hume acerca de la existencia de conexiones necesarias en la naturaleza como un freno a toda especulación metafísica respecto de la modalidad. Dos cuestiones deben tenerse en cuenta. Primero, quienes suscriben una metafísica humeana son en general realistas respecto del mundo exterior. Es por ello que la extensión al plano ontológico de las consecuencias escépticas de la epistemología de Hume han de leerse condicionalmente: si es que efectivamente existe un mundo exterior independiente de las impresiones, entonces en este mundo no hay cosas tales como conexiones necesarias entre eventos. Segundo - y más importante a nuestros fines - , debe notarse que este cuadro metafísico presupone una interpretación tradicional de la filosofía de Hume, a saber, una en la cual niega la existencia de conexiones necesarias o poderes causales reales.

Quienes adoptan una metafísica humeana son llamados, en el contexto del debate acerca de las leyes, Regularistas. El cuadro, para quienes suelen caer bajo ese rótulo, parece ser el siguiente: el mundo está constituido por eventos discretos, cada uno de ellos se autocontiene y es tanto ontológica como causalmente independiente del resto. He aquí una analogía que puede resultar ilustrativa: el mundo es como un mosaico cuyas piezas son estos eventos discretos y causalmente inertes, donde cada pieza es lo que es por sí misma, independientemente del resto, muchas de ellas se presentan en relaciones regulares de semejanza y contigüidad espaciotemporal, pero fuera de ellas ninguna relación de necesidad las conecta. Eso es nuestro mundo, una cosita y luego otra (Lewis 1986, p.ix). La analogía es pertinente en un aspecto más: la independencia de cada una de las piezas no implica que no haya regularidades; por el contrario, con la dedicación suficiente podemos encontrar diversos y complejos patrones en la distribución de las piezas, podemos descubrir que toda pieza roja es contigua de una hexagonal, o que a cada grupo de piezas semejantes en color le sigue un número de piezas verdes determinable por alguna función, etcétera. El punto es que ninguna de esas regularidades identificadas por la investigación empírica está determinada por una necesidad interna (de una pieza implicando a otra) ni externa (del sistema total implicando alguna distribución).

Debemos destacar que, a pesar de que en ocasiones el regularismo es presentado

Principia 19(2): 247-262 (2015). 
como una teoría acerca de las leyes (Psillos 2002, p.137), se trata de una teoría acerca de las regularidades, o las conjunciones constantes en la naturaleza. Dicho de otro modo, según la clasificación que ofrecimos en el apartado anterior respecto del debate metafísico acerca de las leyes, la teoría regularista de las leyes se enmarca, a pesar de su nombre, dentro del AN.

En su forma menos ambiciosa el regularismo se presenta como la mera afirmación de una metafísica humeana que excluye la posibilidad de que la naturaleza contenga leyes reales o cualquier otro vestigio de modalidad no lógica, lo que Mumford (2004) ha bautizado como humeanismo sin leyes (es el caso, por ejemplo, de Kim 1976). Pero algunos han buscado conciliar esta pintura metafísica con la posibilidad de trazar una distinción entre auténticas leyes y meras generalizaciones accidentales. Si bien, como ya hemos notado, esto no constituye la afirmación de un RN, para muchos autores la resolución de la controversia a nivel de los enunciados resulta suficiente para zanjar el debate. Es así que afirman que sin apelar a modalidades de re es posible distinguir a las auténticas leyes como los enunciados que figuran en el mejor sistema deductivo que describe el mundo (equilibrando poder explicativo, simplicidad y otras virtudes no empíricas). Esta posición es conocida como la teoría de los mejores sistemas, o teoría Mill-Ramsey-Lewis (MRL). En el caso de Lewis (1986), la defensa de la teoría MRL está acompañada por la afirmación adicional de lo que se conoce como superveniencia humeana, la idea de que si bien nuestro mundo se corresponde con la descripción no-modal ensayada más arriba y por tanto no contiene leyes, las leyes supervienen sobre las regularidades. Lange (2000) y Beebee (2000) sostienen también este punto de modo semejante.

El problema general con esta tesis consiste en un carácter ambiguo que muchas veces no es subsanado por sus defensores: por una parte la superveniencia de las leyes puede interpretarse como el surgimiento de fenómenos modales sobre una base no-modal (o, dicho a la inversa, como la reductibilidad de hechos modales a una base no-modal); pero, por otra parte, puede entenderse como la posibilidad de seleccionar enunciados legales a partir de una ontología de eventos no-modales. Earman \& Roberts (2005) procuraron brindar una caracterización novedosa de la superveniencia humeana: las leyes naturales supervienen a una base de hechos no-nómicos. Más allá de los detalles vale notar que su formulación no escapa de la ambigüedad señalada. Mientras que comienzan señalando que su tesis es acerca de las leyes de la naturaleza en tanto aspectos objetivos del mundo, a la hora de caracterizar su noción de hecho no-nómico afirman que un hecho es tan solo una proposición verdadera (Earman \& Roberts 2005, p.17). Ahora bien, si las leyes son aquello que superviene sobre cierto tipo especial de proposiciones es difícil ver cómo pueden constituir rasgos objetivos de la naturaleza. Más recientemente Psillos (2014) procura disipar esta ambigüedad caracterizando a las leyes como entidades mereológicas (entidades en la naturaleza) construidas a partir de regularidades.

Principia 19(2): 247-262 (2015). 


\section{Nuevo Hume}

\subsection{El Realismo Escéptico}

La sección previa ha evidenciado que en el debate acerca de las leyes, debate central en el ámbito de la filosofía de la ciencia, se ha etiquetado de "regularistas" o "humeanas" a aquellas teorías (antirrealistas) que presuponen una interpretación estándar u ortodoxa de la filosofía de David Hume. Sin embargo, a partir de la década de 1980 ha adquirido una importancia creciente una interpretación ciertamente novedosa que le atribuye a Hume una actitud realista con respecto a los poderes causales y/o a las conexiones necesarias entre objetos. Este "Nuevo Hume" viene a desafiar la tendencia tradicional que percibe a Hume como un escéptico rabioso con respecto a la posibilidad siquiera de concebir conexiones causales (más allá de las meras conjunciones constantes entre objetos), de donde se sigue que el Nuevo Hume no parece ser demasiado humeano. Sin embargo, autores como John Wright (1983) y Galen Strawson (1989), motivados principalmente por algunos pasajes de la Investigación sobre el conocimiento humano, ${ }^{1}$ han ofrecido argumentos atendibles que vuelven viable la posibilidad de releer a Hume en clave realista. Según esta línea, el filósofo daría por supuesta la existencia de la causación en la realidad a pesar de que nosotros seamos absolutamente ignorantes acerca de su naturaleza (Strawson 1989, p.219).

En la bibliografía especializada suele recibir el nombre de "Realismo Escéptico" la versión más popular del Nuevo Hume, a saber, aquella que sostiene que hay efectivamente poderes causales y (conexiones necesarias entre) objetos en el mundo, pero que tan sólo podemos conocer su existencia (i.e. no sabemos nada acerca de su naturaleza). Esta interpretación es defendida por Janet Broughton, Galen Strawson, John Wright y Edward Craig, entre otros autores. Resulta claro que la posición recibe una denominación que a primera vista genera perplejidad (por combinar dos conceptos que parecen apuntar en direcciones opuestas) porque el intento emprendido consiste en atribuirle a Hume, simultáneamente, un realismo con respecto a los poderes causales (o a las conexiones necesarias entre objetos) y un escepticismo en relación a la posibilidad de conocer la naturaleza concreta de esos poderes causales (o de esas conexiones necesarias). En cualquier caso, creemos que la nomenclatura sólo contribuye a generar confusión y proponemos, en cambio, que esta posición sería mejor caracterizada en términos de la combinación de dos actitudes: un realismo metafísico y un antirrealismo epistémico. Nuestra propuesta para el logro de una mayor claridad terminológica toma mayor fuerza tan pronto se toma nota del hecho de que los nuevos humeanos suelen afirmar que el escepticismo de Hume, en la Investigación... al menos, no es semántico u ontológico, sino más bien epistemológico. Así, Hume pensaría que mientras puede haber, y realmente hay, necesidad en los objetos y, por lo tanto, resulta significativo hablar de necesidad en los objetos (realismo metafísico), no podemos tener ningún conocimiento de su naturaleza (antirrealismo epistémico).

Principia 19(2): 247-262 (2015). 
En este contexto argumentativo cobra importancia la distinción que Hume habría trazado entre una "idea positiva" (o inteligible o derivada de la impresión) y una "idea relativa" (o ininteligible o no derivada de la impresión) de necesidad. Mientras que la idea positiva de necesidad aludiría a la determinación sentida de la mente (the felt determination of the mind), la idea relativa referiría a cualquier cosa que haya en los objetos y a la cual la determinación sentida de la mente de alguna manera "corresponda". Así, los nuevos humeanos sugerirían que lo que Hume quiso decir es que no tenemos otra idea "positiva" de la necesidad fuera de la determinación sentida de la mente. Pero el autor habría dejado abierta la posibilidad de que podamos tener una idea "relativa" de necesidad en los objetos. Y esta idea relativa, a su vez, resultaría suficiente para que hablemos significativamente de necesidad en los objetos (Levi 2000, p.49).

Cabe mencionar que hay también interpretaciones que representan a Hume como algún tipo de "proyectivista" acerca de la causalidad, siendo Simon Blackburn el exponente paradigmático de esta visión que compite con la que hemos expuesto anteriormente y que lee a Hume en clave realista escéptica. Mientras que el realismo escéptico, como hemos visto, considera que el poder causal es alguna propiedad o característica del mundo que no debe su existencia a la existencia de ningún ser humano, el proyectivismo no se molesta con tales cuestiones ocultas y onto-lógicas (Craig 1987, p.113). Sin embargo, creemos que para nuestros fines no vale la pena detenerse en los detalles de la interpretación proyectivista, dado que es perfectamente compatible con el realismo escéptico, de modo que ambas visiones podrían ser verdaderas al mismo tiempo (también, claro está, podrían ser ambas falsas). Por lo demás, si la argumentación de Craig nos resultara convincente, podríamos decir con él que no sólo es posible que ambas visiones sean verdaderas, sino que realmente es bastante plausible que ambas sean verdaderas (Craig 1987, p.114).

\subsection{Las rutas hacia el Realismo Escéptico}

Como hemos visto, interpretar los escritos de Hume a la luz del RE implica atribuirle una actitud realista en cuanto a la existencia de los poderes causales o las conexiones necesarias en la naturaleza, pero escéptica en cuanto a nuestras posibilidades de adquirir un conocimiento positivo de esos poderes o relaciones más allá de su mera afirmación existencial. Según nuestra propia lectura, la conjunción de un realismo metafísico y un antirrealismo epistémico respecto de la modalidad objetiva. En palabras de Strawson, "[Hume] da por sentado que la causalidad efectivamente existe en la realidad, a pesar de que somos totalmente ignorantes de su naturaleza última" (1989, p.219). Wright expresa la misma opinión cuando afirma:

me parece innegable que se pierde el objetivo central de la filosofía escéptica de Hume a menos que se reconozca que éste mantuvo constantemente el

Principia 19(2): 247-262 (2015). 
punto de vista de que hay poderes y fuerzas reales en la naturaleza que no son directamente accesibles a nuestros sentidos. (1983, p.129)

Buena parte de la literatura especializada sobre el Nuevo Hume gravita en torno a las motivaciones para sostener el RE. Dentro de esta producción, sin embargo, hay una enorme variedad de análisis que alternan el foco en aspectos diferentes. Mientras algunos priorizan las reflexiones tendientes a sustentar la viabilidad conceptual de dicha posición, otros se ocupan de buscar apoyo textual en (y rasgos de coherencia con) partes o la totalidad de la obra de Hume. Esto último depende claramente de ciertos énfasis y sus respectivas justificaciones. Para Strawson, por ejemplo, "si [uno] quiere saber lo que Hume pensaba acerca de la causalidad, tiene que dar prioridad a las Investigaciones" (2000, p.31). Es por ello que es dudoso que pueda darse con un modo suficientemente general y a la vez adecuadamente descriptivo para caracterizar la polémica. Con todo, procuraremos ofrecer aquí un mapa general que ilustre al menos parte de los caminos interpretativos por los que los comentadores han arribado al RE.

Podría consensuarse que Hume asume a lo largo de su obra tres perspectivas que parecen entrar en conflicto.

(a) Sostiene creencias sobre objetos, causas, poderes o conexiones necesarias en la naturaleza.

(b) Afirma que no debemos sostener creencias sin un fundamento apropiado en las impresiones (según la Teoría de las Ideas).

(c) Afirma que las creencias sobre objetos, causas, poderes o conexiones necesarias en la naturaleza no tienen un fundamento apropiado en las impresiones (es decir, no son legítimas de acuerdo a la Teoría de las Ideas).

Debe notarse que (a)-(c) no es (ni puede verse cómo podría transformarse en) un conjunto lógicamente inconsistente de proposiciones. Se trata más bien de un conjunto de actitudes doxásticas pragmáticamente inconsistente: uno no podría al mismo tiempo afirmar (a) y hacer lo propio conjuntamente con (b) y (c). Al menos uno de los ítems debe ser resignado en pos de la coherencia pragmática.

De este modo la interpretación tradicional de la filosofía de Hume puede caracterizarse de modo general como la posición que desestima (a). Como es bien sabido existen pasajes en los que Hume parece sostener creencias acerca de objetos, causas, poderes o conexiones necesarias en la naturaleza, sin embargo esas afirmaciones no deben ser tomadas literalmente o deben relativizarse por algún motivo. Popkin (1980), por ejemplo, sostiene que Hume se posicionaba en una suerte de escepticismo pirrónico a partir del cual podía dar cuenta tanto de nuestra legítima tendencia natural a ceder ante ciertas creencias que no podemos menos que aceptar, reconociendo a la vez su falta de fundamento epistémico. 
Por su parte, la estrategia general para una defensa del Nuevo Hume consiste en la afirmación de (a), resignando alternativamente (b) o (c). Es decir, Hume en efecto sostenía creencias sobre objetos, causas, poderes o conexiones necesarias en la naturaleza (según la caracterización del RE), así que, o bien su Teoría de las Ideas debe ser relativizada de algún modo, o bien debe especificarse un sentido en el que dichas creencias tengan algún tipo de fundamento epistémico. La primera de estas estrategias está encarnada por Craig, quien desestima (b) aduciendo que Hume tenía un interés primariamente epistemológico —y no semántico— al formular la teoría de las ideas, limitándola al papel de "un instrumento para descubrir el contenido de nuestros pensamientos" (1987, p.76). En ese contexto es presumible pensar que Hume tuvo "de hecho muy poco interés real en la teoría de las ideas" (1987, p.120).

El camino alternativo hacia el RE es tomado por Strawson y Wright, a grandes rasgos su propuesta consiste en señalar que si bien las creencias de Hume sobre objetos, causas, poderes o conexiones necesarias en la naturaleza confrontan con la Teoría de las Ideas tomada en sentido estricto, hay un sentido más amplio en el que dichas creencias pueden legitimarse. Las razones para este movimiento son diversas. Las más sonantes se vinculan con la distinción entre concebir y suponer. Según la interpretación más estricta de la Teoría de las Ideas, las únicas ideas que albergan un auténtico significado son aquellas que corresponden a impresiones concebidas por la mente. En una lectura más laxa, la acción más débil de suponer la existencia de un objeto, proceso o propiedad (sugerida en algunos pasajes del Tratado) podría dotar de un grado moderado de fundamentación epistémica a las creencias en juego. Por su parte, Ayers (1996) aporta razones históricas que pretenden hacer plausible esta interpretación. Da cuenta así de dos tradiciones en cuanto a la caracterización de la causalidad natural. La primera, en clave aristotélica, identifica el origen de dicho fenómeno con ciertos poderes o esencias causalmente efectivas inmanentes al mundo natural. La segunda es voluntarista, y atribuye a la voluntad divina la proyección de las leyes naturales sobre el mundo. El punto de Ayers es que dado que Hume no podría haber suscripto esta última, toda su argumentación, considerada en el contexto histórico en que se inscribe, debe ser leída como una sutil fundamentación de la existencia de poderes causales naturales.

\section{Nuevo Hume y Leyes naturales}

\subsection{Formulación del Realismo Escéptico en el contexto del debate sobre las leyes de la naturaleza}

Habiéndonos enfocado en los rasgos principales del RE defendido por los promotores del Nuevo Hume, procedemos ahora a indagar en las consecuencias metafísicas que esta interpretación posee en el marco de un debate propio de la filosofía de la ciencia

Principia 19(2): 247-262 (2015). 
contemporánea, el que enfrenta a realistas y antirrealistas nomológicos. Con este fin, intentaremos bosquejar las bases de la posición que resultaría de proyectar el RE al debate sobre las leyes naturales.

Cabe recordar que ante la constatación de la admirable regularidad del mundo natural, se busca el fundamento más apropiado posible para dar cuenta de esta regularidad. Así, quienes asumen un $\mathrm{RN}$, en cualquiera de sus variantes, aseveran que la mejor explicación de la regularidad del mundo exige la referencia a las leyes naturales entendidas como entidades existentes en el mundo. Quienes defienden un AN, por el contrario, consideran superflua la apelación a dudosas entidades metafísicas tales como las leyes. Ellos creen que la suposición de un mundo ontológicamente más modesto resulta suficiente para explicar la regularidad natural, sea porque consideren que esta última es un mero factum que configura una enorme coincidencia feliz sea porque postulen que la existencia de disposiciones o poderes causales en la naturaleza no nos compromete con la asunción de entidades tales como las leyes. Ahora bien, en este contexto argumentativo también cabe preguntarse ¿cuáles son exactamente aquellas tesis que sostendría el nuevo humeanismo, es decir, la posición humeana interpretada a la luz del RE? De acuerdo a los lineamientos trazados con respecto al $\mathrm{RE}$, la mejor explicación de la regularidad del mundo natural sería brindada por la suposición de la existencia de poderes causales y/o de conexiones necesarias en la naturaleza, lo cual sería perfectamente coherente con el realismo metafísico que le atribuimos a la posición. Por otra parte, dado el antirrealismo epistémico que involucra, se hace preciso aclarar la imposibilidad de conocer positivamente la naturaleza concreta de tales poderes causales o conexiones necesarias entre los objetos.

En conclusión, la proyección del nuevo humeanismo o del RE al plano del debate sobre las leyes naturales arroja una posición cuyos defensores hipotéticos suscribirían al menos las siguientes dos tesis: (1) Existen poderes causales y/o conexiones necesarias en el mundo; (2) No podemos conocer la naturaleza de los poderes causales ni de las conexiones necesarias entre objetos.

\subsection{En busca del Nuevo Hume: el lugar del Realismo Escéptico en el debate sobre las leyes de la naturaleza}

Lo expuesto ha tendido a mostrar que el cambio de interpretación que requiere suscribir una lectura en clave de un RE conlleva un cambio radical de perspectiva en cuanto a los fines e implicaciones de la obra de Hume. Por otra parte, no pretendemos novedad al mencionar que la influencia de dicha obra sobre el desarrollo posterior de la historia de la filosofía es inmenso. Aun así creemos que cabe destacarse que esa influencia puede rastrearse mucho más allá de lo estrictamente histórico; muchos problemas, tesis, recursos argumentales y actitudes filosóficas presentes en los escritos de Hume han llegado hasta nuestros días no sólo como meras joyas del panteón

Principia 19(2): 247-262 (2015). 
de la filosofía o piezas de interés para los estudiosos de la modernidad, sino como parte de la actualidad de la reflexión filosófica en campos diversos. Si el humeanismo (en sentido amplio) o las respuestas y soluciones humeanas no son lo que alguna vez pensamos, ello puede tener consecuencias conceptuales de importancia para muchas de nuestras discusiones vigentes, que van más allá de la mera curiosidad histórica. El caso del debate Realismo vs. Antirrealismo Nomológicos es un claro exponente de esa situación. La clave de todo un espectro de posiciones que se han congregado bajo el abrigo de una metafísica humeana está en la interpretación canónica que es puesta en jaque por los defensores del Nuevo Hume. Es por ello que creemos que la reconsideración de las posiciones actuales a la luz de esta interpretación resulta de vital importancia para el debate metafísico en filosofía de la ciencia, incluso para quien no está dispuesto a tirar por la borda una lectura tradicional.

Más allá de estas motivaciones la tarea debe ser llevada a cabo con cierta prudencia. De hecho incluso la transposición de la interpretación tradicional de la filosofía de Hume al campo de la discusión metafísica sobre las leyes no está exenta de dificultades. Por ejemplo, si bien las posiciones humeanas suelen encuadrarse sin más dentro del AN, hay defensores de la superveniencia humeana que aseguran poder dar cuenta de la modalidad y las leyes naturales a partir de un marco que no identifica más que meras conjunciones constantes en el mundo. Es así que esperamos que la posición resultante de reinterpretar la metafísica humeana en los términos del RE presente al menos las mismas dificultades a la hora de ubicar su espacio en el mapa del debate. En parte ello se vincula con el hecho de que lo ofrecido en el apartado precedente no pretende ser la formulación exhaustiva de una posición filosófica acerca de las leyes, sino un mero bosquejo general resultante de perseguir las implicaciones del Nuevo Hume en un territorio remoto. Es por ello que no nos aventuraremos a bautizar a la posición resultante de extender el RE al debate sobre las leyes naturales, refiriéndonos a ella sólo como humeanismo*. Creemos que el ensayar nombres como Realismo Escéptico Nomológico o Nuevo Humeanismo Nomológico puede sugerir algunas implicaciones que exceden lo que estamos dispuestos a afirmar sobre esta posición.

Veamos entonces por fin si alguna de las propuestas consignadas en la sección 2 se acomoda a los presupuestos del RE y, por tanto, del humeanismo*. El componente realista del RE podría hacer pensar que el lugar del humeanismo* está entre las posiciones que se encuadran en el RN. Sin embargo, ese no resulta ser el caso. El RN, tanto en su versión esencialista como en la propuesta de la DTA presupone lo que podríamos llamar un naturalismo epistémico, es decir, la doctrina de que podemos conocer la naturaleza de las leyes. Esto choca de lleno con una de las bases del humeanismo*: los poderes causales o conexiones necesarias en la naturaleza son reales, pero no podemos conocer nada más allá de su existencia. Podría pensarse, sin embargo, que el humeanismo* puede identificarse con una versión del RN. Pero ello 
no es posible, dado que el naturalismo epistémico es esencial tanto al internalismo de Ellis como a la DTA. En el primer caso, puesto que todo nuestro conocimiento del mundo es uno acerca de sus clases naturales y sus relaciones entre ellas, si no disponemos de conocimiento alguno acerca de las propiedades esenciales que determinan y diferencian esas clases, la ciencia no hace más que dar pasos en el aire. Algo semejante ocurre en el caso de la DTA. En primer lugar porque su compromiso con la existencia de leyes es la afirmación del conocimiento de la naturaleza de una relación en particular, a saber, la de necesitación entre universales. Segundo, porque más allá del conocimiento de esta relación (un universal de segundo orden), el compromiso con las leyes deriva de la aplicación de una inferencia a la mejor explicación a partir de ciertas correlaciones entre universales de primer orden. En otras palabras, creemos en leyes porque conocemos la naturaleza de ciertas propiedades del mundo natural y descubrimos una relación metafísica (específica y conocida) entre ellas.

Tal vez encontremos entonces el correlato para el humeanismo* entre las posiciones que, dentro del AN, salvan aún algún componente realista. Nos referimos concretamente al disposicionalismo, que afirma la existencia de conexiones necesarias en la naturaleza pero rechaza a las leyes como parte de la ontología del mundo. Pero nuevamente el naturalismo epistémico sale al cruce de nuestras pretensiones. Toda forma de disposicionalismo presupone que tenemos un contacto más o menos directo con los poderes o disposiciones naturales y, por tanto, un conocimiento positivo acerca de su naturaleza. De hecho, dado que para el disposicionalismo la identidad de una propiedad se agota en su perfil causal, esto es, en los poderes que la constituyen, el conocimiento mínimo requerido para afirmar su existencia incluye el de su naturaleza, a saber, el conocimiento de que se trata de un conjunto de poderes para.... Del mismo modo, la naturaleza de un poder se limita al ser un poder para..., por lo que los criterios mínimos de identidad para afirmar la existencia de tales poderes implican afirmar un conocimiento positivo acerca de qué cosas ese poder puede hacer.

La última vía de escape está en las posiciones que dentro del AN rechazan todo vestigio de modalidad objetiva. Es decir, la última opción es pensar que el humeanismo* coincide con el humeanismo. Algo de plausibilidad puede agregársele a esta sugerencia si se considera que algunas formas de superveniencia humeana pretenden dar cuenta de aspectos modales o nomológicos del mundo. Sin embargo este camino también está cerrado, puesto que toda forma de humeanismo - incluso aquellas que pretenden reducir la modalidad a las conjunciones constantes o las leyes a los axiomas de los mejores sistemas explicativos- supone la negación de que existan poderes causales o conexiones necesarias en la naturaleza, sea conocidos, sea como meros postulados existenciales. No hay modo en el que pueda resultar verdadero que humeanismo* $=$ humeanismo.

El diagnóstico entonces no puede ser otro que la constatación de que ninguna de

Principia 19(2): 247-262 (2015). 
las posiciones que configuran el debate actual acerca de las leyes de la naturaleza coincide con las bases de lo que constituiría una posición humeana interpretada a la luz del RE, es decir, con lo que hemos llamado humeanismo*.

\section{Conclusión}

Nuestro trabajo no tuvo por objeto destacar los méritos de ninguna de las posiciones dentro de los debates que fueron objeto de análisis. Nos hemos limitado a la exposición de las opiniones vigentes sobre la metafísica de las leyes trazando un mapa que, por otra parte, constituye un escenario casi universalmente asumido por los autores. En cuanto a la polémica en torno al Nuevo Hume, nuestra reconstrucción de las razones que motivan el RE tuvo por objeto clarificar las consecuencias metafísicas de esa interpretación, de ningún modo la pregunta central de este trabajo ni las conclusiones a las que arriba requieren ni sugieren que dicha interpretación sea correcta. La importancia que ella ha adquirido en la discusión experta sobre la obra de Hume basta para motivar la revisión de sus consecuencias en la filosofía de la ciencia, y más concretamente, en la polémica sobre las leyes.

Alguien, sin embargo, podría objetarnos en términos semejantes a los siguientes: "las trasposiciones actuales de los resultados de Hume presuponen una interpretación tradicional, por lo que todas las revisiones a la luz del Nuevo Hume pueden ser reemplazadas por una mera aclaración del tipo 'humeano (bajo la interpretación estándar)', aclaración que, por otra parte, ya puede presuponerse tácitamente presente en todas las posiciones cuya revisión se reclama". En síntesis, podría argüirse que la revisión que proponemos es irrelevante en el contexto de los debates actuales sobre las leyes naturales. Pero la importancia de nuestra pregunta no es realmente afectada por esta crítica. Imaginemos que alguien encontrara el modo de defender plausiblemente que Marx no mantuvo en realidad jamás una actitud teórica hostil hacia la primacía del Estado o hacia las democracias liberales. ¿No sería eso motivo suficiente para legitimar la pregunta acerca de cuáles serían las consecuencias de esa lectura sobre las posiciones neomarxistas, o incluso sobre debates filosóficos en los que el marxismo clásico tuvo una influencia decisiva? Creemos que la actualidad del pensamiento de Hume resulta fundamento suficiente para la relevancia de una investigación como la que intentamos llevar a cabo aquí.

Pero si se aceptan los resultados de las páginas precedentes nuestra revisión sobre los devenires del humeanismo tiene una dimensión adicional de interés. Los principios del RE, extrapolados al debate sobre las leyes naturales, resultan en una posición que a efectos de mantenernos neutrales llamamos humeanismo*. Razones incontestables muestran que ninguna de las posiciones actualmente formuladas en el marco de ese debate coincide con el humeanismo*. Es por ello que la revisión emprendida 
nos deja frente a los cimientos de una posición novedosa en el terreno de la polémica contemporánea. El desarrollo de sus pormenores y su relación con otras propuestas filosóficas conocidas resultan en una ruta prometedora para futuras investigaciones, quedando fuera del alcance de este trabajo. Baste sin embargo decir que la afirmación existencial de poderes causales en la naturaleza y la restricción epistémica sobre sus cualidades intrínsecas parece vincular estrechamente a la posición que llamamos humeanismo* con las bases del Realismo Estructural ${ }^{2}$ de Worrall (1989) y Zahar (1994).

Por lo demás, este recorrido que nos llevó desde el RE al centro de la filosofía de la ciencia contemporánea es un testimonio más de la actualidad y vigencia del pensamiento de Hume. Quien, al parecer, tiene todavía mucho por decirnos.

\section{Agradecimientos}

Una versión previa del presente trabajo fue presentada en el marco del V Encontro Hume, celebrado en la UFSC en 2015. Queremos agradecer a Jaimir Conte y a Flávio Miguel de Oliveira Zimmermann por el cálido recibimiento que nos brindaron en ocasión del evento y por sus valiosos aportes críticos. Agradecemos a demás al resto de los asistentes por sus comentarios, que sin dudas permitieron mejorar la versión final de este trabajo; entre ellos especialmente a Silvio Chibeni, cuyo interés en nuestra contribución nos honró profundamente.

\section{Referencias}

Armstrong, D. 1978. A Theory of Universals. Cambridge: Cambridge University Press.

. 1983. What is a Law of Nature? Cambridge University Press.

- 1991. What Makes Induction Rational? Dialogue 30: 503-11.

- 1993. The Identification Problem and the Inference Problem. Philosophy and Phenomenological Research 53: 421-22.

Ayers, M. 1996. Natures and laws from Descartes to Hume. In: G. A. J. Rogers; S. Tomase1 li (eds.) The Philosophical Canon in the Seventeenth and Eighteenth Centuries: Essays in Honour of John W.Yolton. Rochester NY: University of Rochester Press.

Beebee, H. 2000. The Nongoverning Conception of Laws of Nature. Philosophy and Phenomenological Research 61: 571-94.

Borge, B. 2014. Los orígenes del Realismo Estructural: rastreando la tradición estructuralista en Filosofía de la Ciencia. Principia 18(3): 295-322.

Craig, E. 1987. The Mind of God and the Works of Man. Oxford: Clarendon Press.

- 1987. Hume on causality: projectivist and realist? In: R. Read; K. Richman (eds.) The New Hume Debate, p.113-21, London: Routledge.

Dretske, F. 1977. Laws of Nature. Philosophy of Science 44: 248-68.

Ellis, B. 2001. Scientific Essentialism. Cambridge: Cambridge University Press.

Earman, J.; Roberts, J. T. 2005. Contact with the nomic: A challenge for Deniers of Humean Supervenience about laws of nature part II: The epistemological argument for Humean Supervenience. Philosophy and Phenomenological Research 71(1): 1-22.

Principia 19(2): 247-262 (2015). 
Kim, J. 1976. Events as property exemplifications. In: Supervenience and Mind. Cambridge:

Cambridge University Press, p.33-52, 1993.

Lange, M. 2000. Natural Laws in Scientific Practice. Oxford: Oxford University Press.

Levy, K. 2000. Hume, the New Hume and Causal Connections. Hume Studies XXVI(1): 41-76

Lewis, D. 1973. Counterfactuals. Cambridge: Harvard University Press.

- 1986. Philosophical Papers, Volume II. New York: Oxford University Press.

Mumford, S. 2004. Laws in nature. London: Routledge.

Popkin, R.H. 1980. The High Road to Pyrrhonism. San Diego, CA: Austen Hill.

Psillos, S. 2002. Causation and Explanation. Chesham: Acumen.

- 2014. Regularities, Natural Patterns and Laws of Nature. Theoria. Revista de Teoría, Historia y Fundamentos de la Ciencia 29(1): 9-27.

Strawson, G. 1989. The Secret Connexion: Causation, Realism and David Hume. Oxford: Clarendon Press.

- 2000. David Hume: objects and power. In: R. Read; K. Richman (eds.) The New Hume Debate, p.31-51, London: Routledge.

Tooley, M. 1977. The Nature of Laws. Canadian Journal of Philosophy 7: 667-98.

. 1987. Causation. Oxford: Clarendon Press.

Worall, J. 1989. Structural Realism: The Best of Both Worlds? Dialectica 43: 99-124.

Wright, J. P. 1983. The Sceptical Realism of David Hume. Manchester: Manchester University Press.

Zahar, E. 1994. Poincaré's Structural Realism and his Logic of Discovery. In: G. Heinzmann et al. (eds.) Henri Poincaré: Akten des Internationalen Kongresses in Nancy.

BRUNO BORGE
Universidad de Buenos Aires - ANPCyT
brunojborge@gmail.com
ROBERTO AZAR
Universidad de Buenos Aires
robertoazar86@gmail.com

\section{Notas}

${ }^{1}$ Hay consenso en que esta obra constituye la exposición más coherente y madura de las ideas de David Hume.

${ }^{2}$ Para un panorama histórico-conceptual del Realismo Estructural puede consultarse Borge (2014).

Principia 19(2): 247-262 (2015). 